\title{
ESTHETIC REHABILITATION OF CORONAL FRACTURES OF MAXILLARY ANTERIOR TEETH AFTER PULPOTOMY: REPORT OF CASES.
}

\author{
Dr.Alpa Gupta ${ }^{1}$ Dr. Hans Raj Saini ${ }^{2}$ Dr. Jigyasa Duhan ${ }^{3}$ Dr. Shashi Bala ${ }^{4}$ \\ ${ }^{1}$ Post Graduate Demonstrator, Department of Conservative Dentistry \& Endodontics, PGIDS, Rohtak, Haryana (India) \\ ${ }^{2}$ Post Graduate Demonstrator, Department of Conservative Dentistry \&Endodontics, PGIDS, Rohtak, Haryana (India) \\ ${ }^{3}$ Professor, Department of Conservative Dentistry \&Endodontics, PGIDS, Rohtak, Haryana (India) \\ ${ }^{4}$ Senior Professor and Head, Department of Dental Materials, PGIDS, Rohtak, Haryana (India) \\ Correspondence Address: \\ ${ }^{1}$ Mobile: 919050312010 Email: alpagupta2008@gmail.com
}

\begin{tabular}{|l} 
Received : \\
$24^{\text {th }}$ Sept, 2013 \\
Accepted: \\
$29^{\text {th }}$ Nov, 2013 \\
Available online: \\
$28^{\text {th }}$ Dec, 2013
\end{tabular}

Received :

$24^{\text {th }}$ Sept, 2013

Accepted:

$28^{\text {th }}$ Dec, 2013

\section{ABSTRACT}

\begin{abstract}
The present case report describes management of two cases with complicated coronal fracture where fractured fragments were reattached, before reattachment of fractured fragments pulpotomy was performed in both cases using different pulpotomy agents, calcium hydroxide in patient with immature apex and mineral trioxide aggregate (MTA) in patient where root development was complete. Both the patients were evaluated for sign and symptoms for a period of 18 months with successful outcome.
\end{abstract}

Keywords: Pulpotomy, Tooth fracture, Esthetic

\section{INTRODUCTION}

Traumatic injuries to teeth and their supporting tissues usually occur in young people and damage may vary from enamel fracture to avulsion, with or without pulpal involvement or alveolar bone fracture. The percentage of simple coronal fracture due to trauma involving enamel in children's teeth is 28 $44 \%$ while that of complex fracture involving pulp is found to be $11-15 \% .^{1,2}$ Most of these injuries occur in permanent maxillary incisors before complete root formation and can lead to pulp inflammation or necrosis. ${ }^{3}$ The restoration of such kinds of fractures is esthetically and functionally very important,and such teeth have commonly been restored using composite resin. But the disadvantages of such a treatment are rapid wear and discoloration of restoration. ${ }^{4}$

The best treatment option for coronal fractures is the restoration of a fractured tooth with its own fragment. ${ }^{5-8}$ With the help of this approach the colour and size of original tooth can be maintained, more over it provides the patient with an emotionally and socially positive response due to the protection of natural tooth structure. ${ }^{7-10}$ The disadvantage of wear rate of restoration can be easily overcome through this method. Lastly the procedure is rapid, conservative and economical. ${ }^{7-10}$ The present case report evaluated the reattached fragments of teeth both clinically as well as radiographically.

\section{CASE 1}

A ten years old male reported to the department of conservative dentistry and endodontics with coronal fracture of maxillary central incisor. Patient had an accidental fall 6 hours ago and he carried his fractured fragment along with. Informed consent was obtained from the parents. Just before the treatment, the patient was clinically and radiographically examined. On clinical examination complicated crown fracture was present with pulp exposure (Figure 1). No associated soft/hard tissue injury was present. Radiographic examination revealed the pulpal exposure of 21 with open apex (Figure 2). Before the treatment, the periodontal tissues around the affected teeth were examined with a periodontal probe in order to determine the extent of coronal fracture, and presence or absence of vertical root fracture. The clinically conducted periodontal assessment showed no vertical root fracture. The fracture line was at the supra gingival level. History 
of pulp sensitivity was taken from the patient and no change in tooth colour was observed. As the response of the tooth having trauma to the vitality test, in the first visit is not reliable the vitality test was carried out at the follow-up visits after treatment. ${ }^{11}$ First of all cervical pulpotomy was performed in 21 whose pulp was exposed. The teeth were isolated by rubber dam, access to the coronal pulp was achieved using a diamond bur and coronal pulp tissue up to the cervical constriction was removed with a sharp excavator. Haemorrhage from the exposed pulp was controlled by the application of a sterile moist cotton pellet for 3-5 minutes. A calcium hydroxide paste was then applied to the exposed pulp. Afterwards, the coronal fragment was bonded with composite resin (Figure 3, 4). Some grooves were created on the internal and external surface of tooth to increase the bond strength. Traumatic occlusion was checked. Patient was put on soft diet and instructed not to bite anything hard from that particular tooth. The parents and the patient were informed about the importance of maintaining meticulous oral hygiene and regular follow-ups. Further assessments were made at 1, 3, 6, 12, 18 months. In clinical assessment the patient was evaluated for any kind of tooth discoloration, pain and sensitivity which were found to be negative. The vitality tests were positive at follow up visits. Radiographic analysis was performed and no radiolucency was found at the periapical area more over the closure of root apex was observed with the subsequent follow up at 18 months (Figure 5).

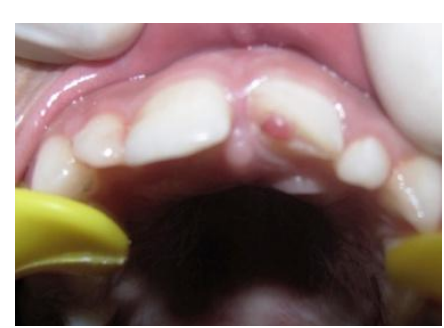

Figure 1

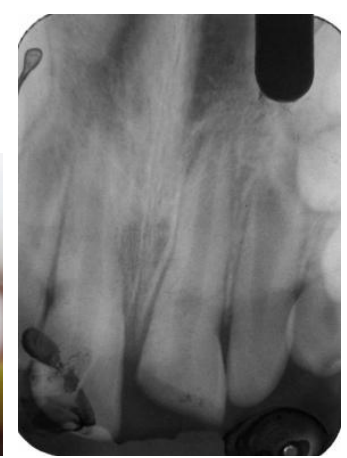

Figure 2
Figure 1: Preoperative view of case 1 showing coronal fracture and pulp exposure, Figure 2: Preoperative radiograph showing fracture and open apex in 21

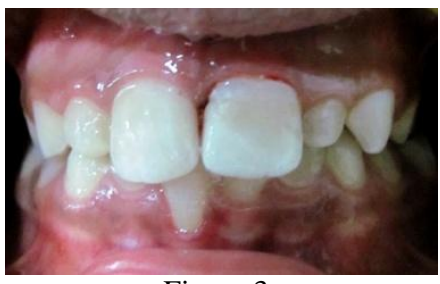

Figure 3

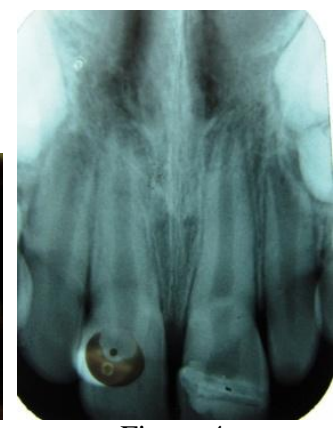

Figure 4

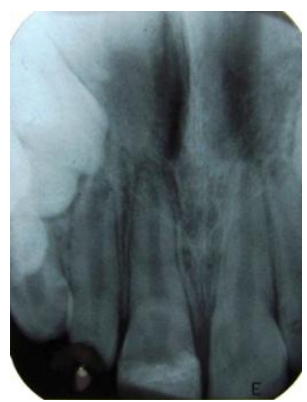

Figure 5

Figure 3: Restored coronal fracture with original fractured segment, 4: Radiographic view after reattachment, Figure 5: 18 months follow up radiograph showing closure of apex

\section{CASE 2}

Second case describes a 20 years old, healthy female patient who reported to the department with chief complaint of broken coronal part of her maxillary central incisor due to an accidental fall. The time lag between the injury and visit was 3 hours. All the clinical, periodontal and radiographic examinations were performed as in case 1 (Figure 6, 7, 8). The findings were exactly similar, except that the root apex was closed in tooth11. Similar treatment protocol was followed as in case 1, the difference lied in the material used for the pulpotomy procedure. Instead of calcium hydroxide, mineral tri-oxide aggregate (1-2 mm) was used as pulpotomy agent over which a layer of glass ionomer cement was placed and finally coronal fragment was bonded with composite resin (Figure 9) All the radiographic and clinical assessments were performed at 1, 3, 6, 12 and 18 months. Patient reported with no sign and symptoms at follow up visits. Radiographic assessment showed no periapical radiolucency, even at 18 months follow up (Figure 10, 11). 

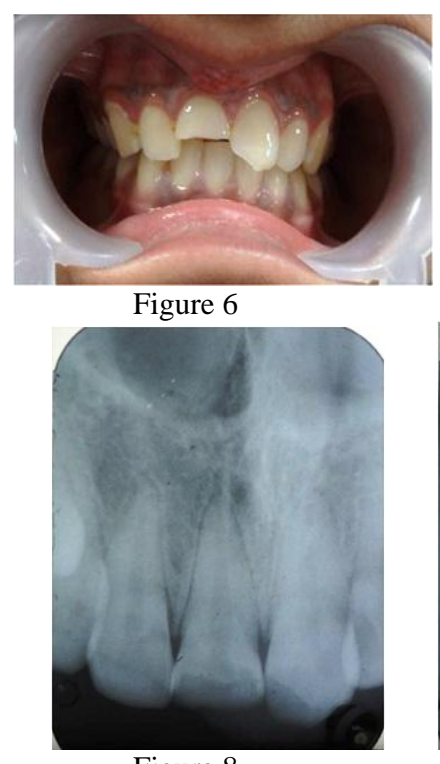

Figure 8

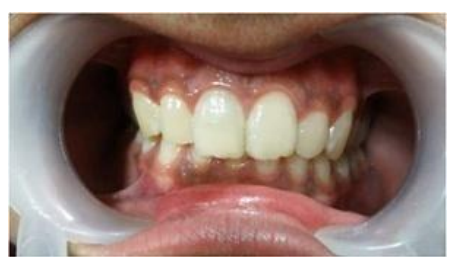

Figure 10

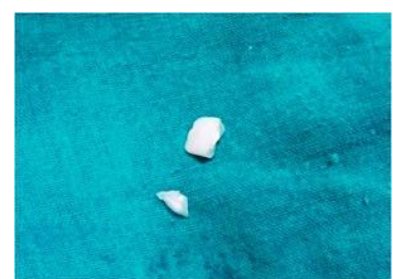

Figure 7

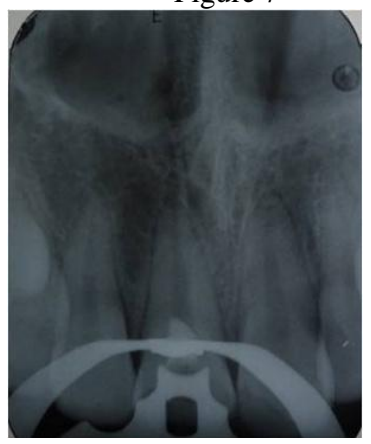

Figure 9

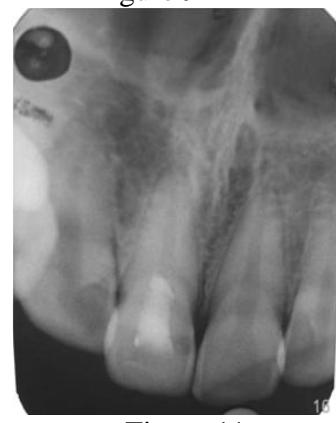

Figure 11
Figure 6: Preoperative view of case 2 showing coronal fracture, Figure 7: Fractured segments, Figure 8: Preoperative radiograph showing fracture of case 2, Figure 9: Radiographic view showing pulpotomy, Figure 10: Clinical view after 18 months, Figure 11: Radiographic follow up after 18 months.

\section{DISCUSSION}

The type of treatment given to the injured tooth is related to the fracture line. Literature supports cervical amputation of teeth with complicated coronal fractures (enamel + dentin + pulp exposure) ${ }^{12}$, no endodontic intervention is required to preserve the pulp vitality. The use of calcium hydroxide as pulpotomy agent leads to systematic recovery with calcific barrier in 2-3 months. ${ }^{13}$ Researchers preferred the use of MTA (mineral tri-oxide aggregate) as a potential medicament in pulpotomies, direct pulp capping, and numerous other dental applications. ${ }^{14}$ GIC over MTA has an added advantage in the form of better coronal sealing. ${ }^{14}$

The clinical and radiographic endodontic assessment at follow-up after the treatment included discoloration of the remaining tooth part, vitality, and tenderness to percussion, any kind of sensitivity and pain, formation of physiologic apex, apical radiolucency, and pulp canal obliteration. Fragment detachment was not observed in any case. Creation of internal and external grooves along the fracture line and covering it with composite resin might have contributed to the bond strength. A study reported reattachment of the tooth fragment using a flowable composite resin with successful results after 2.5 years. ${ }^{15}$ Additional preparations were supported in another study as they were required to increase the bond strength 16,17

Conclusion and Clinical implications: Evaluation of type of fracture, fracture line and the fracture segment is of utmost importance for planning the treatment of traumatized/ fractured teeth. Proper case selection is the key to success. Reattachment of fractured fragment leads to excellent esthetics with good bond strength. It is convenient, easy and quite economical option.

\section{REFERENCES}

1. Kirzioglu Z, OzayErturk MS, Karayilmaz H. Traumaticinjuries of the permanent incisors in children in southernTurkey: a retrospective study. Dent Traumatol 2005;21:20-5

2. Kargul B, Caglar E, Tanboga I. Dental trauma in Turkishchildren, Istanbul. Dent Traumatol 2003;19:72-5

3. Andreasen JO, Andreasen FM. Textbook and color atlas oftraumatic injuries to the teeth. 4th ed. Oxford: Blackwell;2007.

4. Powers JM. Cements. In: Craig RG, Powers JM, editors.Restorative dental materials, 11th edn. St. Louis, MO: Mosby;2002. p. 618-22.

5. Curzon MEJ, editor. Special tests: radiographs and sensibility(vitality) testing. In: Handbook of dental trauma: a practicalguide to the treatment of trauma to the teeth. Cornwall: MPGBooks Ltd; 1999. p. 18-27.

6. Andreasen JO, Andreasen FM, editors. Crown fractures. In:Essentials of traumatic injuries to the teeth. Copenhagen:Munksgaard; 1992. p. 29-46.

7. Kirzioglu Z. Restoration of a fractured incisor by using originaltooth fragment: a case report. Ataturk Univ Dis HekFakDerg 1994;4:120-4

8. Simonsen RJ. Restoration of a fractured central incisor usingoriginal tooth fragment. $\mathrm{J}$ Am Dent Assoc 1982;105:646-8

9. Worthington RB, Murchison DF, Vandewalle KS. Incisal edgereattachment: the effect of preparation utilization and design.Quintessence Int 1999;30:637-43

10. Dean JA, Avery DR, Swartz ML. Attachment of anterior toothfragments. Pediatr Dent 1986;8:139-43

11. Roberts G, Longhurst $P$. Oral and dental trauma in childrenand adolescents. New York: Oxford; 1996. 
12. Landis JR, Koch GG. The measurement of observer agreementfor categorical data. Biometrics 1997;33:159-74

13. Andreasen JO, Andreasen FM, Bakland LK, Flores MT.Traumatic dental injuries, 2nd edn. Copenhagen: BlackwellMunksgaard; 2003.

14. Torabinejad M, Chivian N. Clinical applications of mineral trioxide aggregate. J Endod 1999; 25:197-205.

15. Cengiz SB, Kocadereli I, Gungor HC, Altay N. Adhesivefragment reattachment after orthodontic extrusion: a casereport. Dent Traumatol 2005;21:60-4
16. Demarco FF, Fay R-M, Pinzon LM, Powers JM. Fractureresistance of re-attached coronal fragmentsinfluence of differentadhesive materials and bevel preparation. Dent Traumatol 2004;20:157-63

17. De Santis R, Prisco D, Nazhat SN, Riccitiello F, Ambrosio L,Rengo $\mathrm{S}$ et al. Mechanical strength of tooth fragment reattachment.J Biomed Mater Res 2001;55:629-36 